\title{
TEMPORAL AND SPATIAL CHANGES OF DROUGHT IN BEIJING-TIANJIN-HEBEI REGION BASED ON REMOTE SENSING TECHNOLOGY
}

\author{
Lin Xingchen, Chen Jianjun*, Lou Peiqing
}

College of Geomatics and Geoinformation, Guilin University of Technology, Guilin 541004,

China-linxingchen2019@126.com (L.X.); chenjj@glut.edu.cn (C.J.); gislou@126.com (L.P.)

KEY WORDS: Beijing-Tianjin-Hebei region; remote sensing; drought monitoring; TVDI; temporal and spatial variation

\begin{abstract}
:
Drought is an extremely complex natural disaster phenomenon. Sustained drought will lead to the aggravation of water shortage, food production reduction, land desertification and ecological crisis, which will have a great impact on social and economic development, industrial and agricultural production and ecological environment. In recent years, human activities have intensified, the global climate has been warming, and the frequency and intensity of extreme events such as drought have been continuously strengthened, which has been widely concerned by scholars at home and abroad. The Beijing-Tianjin-Hebei region, as the political and cultural center of China, is seriously affected by the drought, which has a certain impact on the social economy of the region. Therefore, it is of great practical significance to carry out remote sensing drought monitoring and understand the temporal and spatial characteristics of drought. Based on MOD13A2 and MOD11A2 in MODIS products, this paper constructed the NDVI-Ts feature space to obtain the Temperature Vegetation Dryness Index (TVDI) in Beijing-Tianjin-Hebei region, and analyzed the spatial and temporal variation characteristics of drought in Beijing-Tianjin-Hebei region from 2001 to 2014 with TVDI as the drought index. The results showed that: (1) the NDVI-Ts feature space in the Beijing-Tianjin-Hebei region showed that when the value of NDVI rose from 0 to 1 , the maximum temperature of the surface gradually decreased, while the minimum temperature gradually rose. Both of them had a linear relationship with NDVI, and their spatial shape was similar to a triangle, indicating that the study of drought in Beijing-Tianjin-Hebei was effective by using this spatial feature; (2) the Beijing-Tianjin-Hebei region experienced drought every year in the period of 2001-2014, and the drought was more serious in 2001, 2004, 2008, 2009, 2011 and 2012; (3) The drought in the Beijing-Tianjin-Hebei region was widespread, and the severely arid regions were mainly concentrated in the southern and central regions. In terms of drought intensity, the most frequent occurrences in the period of 2001-2014 were Xingtai, Hengshui, Shijiazhuang, and Handan, and the annual drought in 14 years; the least number of occurrences was Chengde, a total of 4 times; the number of occurrences was second only to Chengde, Tangshan, Zhangjiakou, Qinhuangdao, a total of 7 times. Our results indicated that the Beijing-Tianjin-Hebei region was prone to drought and the drought degree was severe.
\end{abstract}

\footnotetext{
* Corresponding author
} 


\section{INTRODUCTION}

As one of the most complicated climate disasters that have the most serious impact on human society, drought has the characteristics of high frequency, long duration and wide range of influence, which is an important problem that plagues the development of today's society (Liu et al, 2019). As the main producing area of wheat in China, the Beijing-Tianjin-Hebei region is a temperate monsoon climate with uneven annual precipitation distribution, increased demand for water resources and increased pollution, resulting in frequent drought disasters in the Beijing-Tianjin-Hebei region, seriously affecting residents' living, social and economic development. Environmental improvements have also caused economic losses to some extent (Nait-Ali et al, 2017; Centritto et al, 2011). Therefore, the analysis of the spatial and temporal changes of drought in the Beijing-Tianjin-Hebei region is of great significance for alleviating the loss of drought disasters, rationally planning limited water resources and ensuring its economic and social development.

Goward and Hope used NOAA-AVHRR data to find that the Normalized Difference Vegetation Index (NDVI) and Surface Temperature (Ts) vary with soil moisture (Goward, Hope, 1989); Price and Carlson et al. The scatter plots showing NDVI as the abscissa and Ts as the ordinate are generally triangular (Price, 1990; Carlson et al, 1994); Nemani, Moran, etc. further discover that the feature space of Ts-NDVI is trapezoidal (Nemani et al, 1993; Moran et al, 1994); eventually Sandholt et al. The Temperature Vegetation Dryness Index (TVDI) was proposed and used as an important indicator for monitoring drought by remote sensing (Sandholt et al, 2002). TVDI has been widely used as soon as it is proposed. Qi et al. used TVDI to evaluate the distribution of drought levels across the country and carried out drought monitoring, and achieved good results (Qi, 2004); Chen et al. compared the drought monitoring results of TVDI with the research situation and found that TVDI can monitor the drought well in time and accurately evaluate the drought situation of the grassland. (CHEN et al, 2013); Bai uses the normalized vegetation index NDVI and the enhanced vegetation index EVI and the surface temperature to construct the temperature-vegetation feature space, and finds that the TVDI calculated by the two vegetation indices is inversion of soil moisture. Both have higher precision (Bai, 2014).
In this paper, the long-term sequence MODIS data (MOD13A2 and MOD11A2) from 2001 to 2014 were used to analyze the spatial and temporal changes of drought in the Beijing-Tianjin-Hebei region. Based on the remote sensing monitoring model of temperature vegetation drought, the dry-wet edge equation was constructed to obtain the annual temperature vegetation drought index TVDI. Finally, the drought in the Beijing-Tianjin-Hebei region was monitored by the TVDI model, and the spatial and temporal distribution of drought in the Beijing-Tianjin-Hebei region from 2001 to 2014 was analyzed.

\section{DATA SOURCE AND PROCESSING METHODS}

\subsection{Overview of the study area}

The Beijing-Tianjin-Hebei region is China's "Capital Economic Circle", located in the northern part of the North China Plain, between $36^{\circ} 05^{\prime} \sim 42^{\circ} 37^{\prime} \mathrm{N}, 113^{\circ} 27^{\prime} \sim 119^{\circ} 50^{\prime} \mathrm{E}$ (Fig. 1).

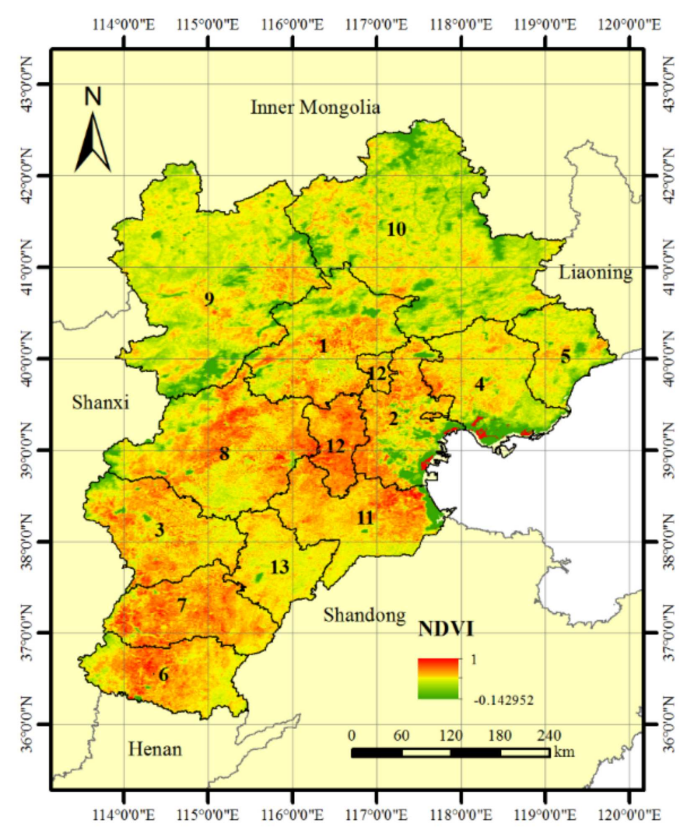

Figure 1.Location of the Beijing-Tianjin-Hebei region and TVDI distribution in 2001 (1 Beijing 2 Tianjin 3 Shijiazhuang 4

Tangshan 5 Qinhuangdao 6Handan 7 Xingtai 8 Baoding 9 Zhangjiakou 10 Chengde 11 Zhangzhou 12 Langfang 13 Hengshui) 
It is bordered by the Yanshan Mountains in the north, the North China Plain in the south, the Taihang Mountain in the west, and the Bohai Bay in the east. The terrain is higher in the northwest and north, and the terrain is flatter in the south and east. From the northwest, the Yanshan-Taihangshan mountain system gradually transitions to the plain in the southeast, showing the topographical features of the northwest high and southeast low (Zhang et al, 2017). From the perspective of geomorphology, the area contains a variety of geomorphological features, but still dominated by plain landforms, along the coast of the shoal and wetlands. The Haihe River Basin spreads in the form of fan-shaped water system in the Beijing-Tianjin-Hebei region. The climate is typical of temperate semi-humid and semi-arid continental climate, and the spatial distribution of annual precipitation is affected by factors such as atmospheric circulation and geographical regions. The distribution is uneven, mainly due to the large precipitation on the side of Yanshan and Taihang Mountain. The precipitation in the plain area is generally higher than that in the dam area, and the precipitation in the east is significantly larger than that in the west.

\subsection{Data sources and pre-processing}

2.2.1 Data source: The 2001-2014 surface temperature data (Ts) and normalized vegetation index (NDVI) data used in this paper are from the NASA (National Aeronautics and Space Administration) data sharing website (https://www.nasa.gov/). The MODIS MOD13A2 and MODIS MOD11A2 image data are widely used for large-area drought monitoring. The data format is HDF and the spatial resolution is $1 \mathrm{~km}$.

2.2.2 Data preprocessing: (1) Due to the large amount of data in this study, the data is processed in batch processing. First, the MRT toolbox is used to perform format conversion, projection coordinate conversion, and the like on the downloaded data MOD13A2 and MOD11A2, and the coordinates used in the study are the WGS84 coordinate system. In ENVI 5.3, the administrative vector boundaries of the Beijing-Tianjin-Hebei region are used to tailor the data required for the study area.(2) In the interannual variation analysis, this study averages the NDVI and LST data from April to October every year to prevent image outliers from affecting the processing results.

\subsection{Research methods}

The Temperature Vegetation Drought Index (TVDI) was first proposed by Sandholt. By constructing the NDVI-Ts feature space, the dry-wet edge equation is calculated, and finally TVDI (Fig. 2) is obtained. The NDVI-Ts feature space is approximated as a triangle (Sandholt et al, 2002). The specific formula is:

$$
\begin{gathered}
\text { TVDI }=\frac{\mathrm{Ts}-\mathrm{Ts}_{\min }}{\mathrm{Ts}_{\max }-\mathrm{Ts}_{\min }} \\
\mathrm{Ts}_{\min }=\mathrm{a}_{1}+\mathrm{b}_{1} \times \mathrm{NDVI}, \mathrm{Ts}_{\max }=\mathrm{a}_{2}+\mathrm{b}_{2} \times \mathrm{NDVI}
\end{gathered}
$$

Where: Ts represents the surface temperature of any pixel; represents the corresponding wet edge; represents the corresponding dry edge; represents the coefficient of the fit equation of the dry and wet edges in the feature space, respectively. $\mathrm{TVDI}=1$ on the dry side and $\mathrm{TVDI}=0$ (Sun et al, 2014) on the wet side.

When calculating TVDI, we can determine the dry and wet edges based on the NDVI value of the pixel, and then determine the TVDI value by the location of the pixel's surface temperature in the feature space (Liu et al, 2013). The closer TVDI is to 0 , the higher the soil moisture and the lower the degree of drought; the closer TVDI is to 1 , the lower the soil moisture and the higher the degree of drought (Zhang et al, 2019).

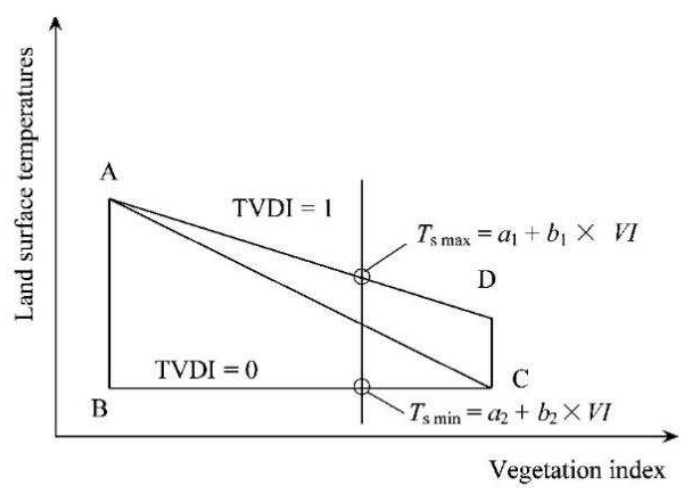

Figure 2. TVDI definition

TVDI mainly depends on the fitting equation of dry and wet edges of feature space, and TVDI is between $0-1$. The larger the TVDI value is, the more dry the soil is, the smaller the value is, the more moist the soil is. Yao et al. classify the arid regions based on TVDI (Table 1), which better reflects the local drought conditions (Wang et al, 2013). Based on this, this study will sample the partitioning criteria in subsequent analysis. 


\begin{tabular}{ccc}
\hline RANGE & CLASS & TVDI \\
\hline 1 & Very wet & $0<\mathrm{TVDI}<0.2$ \\
2 & Wet & $0.2 \leq \mathrm{TVDI}<0.4$ \\
3 & Normal & $0.4 \leq \mathrm{TVDI}<0.6$ \\
4 & Drought & $0.6 \leq \mathrm{TVDI}<0.8$ \\
5 & Very Drought & $0.8 \leq \mathrm{TVDI}<1$ \\
\hline
\end{tabular}

Table 1. Classification of drought levels using TVDI as an indicator

\section{RESULT AND ANALYSIS}

\subsection{TVDI feature space analysis}

In the process of calculating TVDI, the dry and wet edges of the pixel can be determined according to the NDVI value of the pixel, and the value of the TVDI can be determined by the position of the surface temperature of the pixel in the feature space. The required NDVI data and its corresponding maximum land surface temperature and minimum land surface temperature data are extracted from ArcGIS. Then use NDVI as the abscissa and Ts as the ordinate to make a scatter plot. The NDVI-Ts feature space from 2001 to 2014 is obtained respectively, and the trend line and dry-wet edge equations are fitted (Table 2). The abscissa in the scatter plot starts from 0.2, mainly because the vegetation coverage of the study area cannot be reasonably indicated when the NDVI is less than 0.2 .

It can be observed from Table 2 that when the value of NDVI rises from 0 to 1 , the maximum temperature of the surface gradually decreases, and the minimum temperature gradually rises. Both of them have a linear relationship with NDVI, and the shape is similar to a triangle. The results are consistent with previous studies.

\begin{tabular}{llc}
\hline YEAR & Dry boundary equation & Wet edges equation \\
\hline 2001 & $\mathrm{Ts}_{\max }=-28.5424 \mathrm{NDVI}+57.0472$ & $\mathrm{Ts}_{\min }=-0.531390 \mathrm{NDVI}+23.4932$ \\
2002 & $\mathrm{Ts}_{\max }=-41.7940 \mathrm{NDVI}+67.0982$ & $\mathrm{Ts}_{\min }=1.18706 \mathrm{NDVI}+22.8070$ \\
2003 & $\mathrm{Ts}_{\max }=-43.6765 \mathrm{NDVI}+68.3471$ & $\mathrm{Ts}_{\min }=-1.33703 \mathrm{NDVI}+22.7834$ \\
2004 & $\mathrm{Ts}_{\max }=-20.1165 \mathrm{NDVI}+49.4965$ & $\mathrm{Ts}_{\min }=-0.663994 \mathrm{NDVI}+22.9989$ \\
2005 & $\mathrm{Ts}_{\max }=-40.2898 \mathrm{NDVI}+66.0693$ & $\mathrm{Ts}_{\min }=0.371505 \mathrm{NDVI}+22.8104$ \\
2006 & $\mathrm{Ts}_{\max }=-39.2859 \mathrm{NDVI}+64.3573$ & $\mathrm{Ts}_{\min }=-0.795342 \mathrm{NDVI}+22.9042$ \\
2007 & $\mathrm{Ts}_{\max }=-30.4967 \mathrm{NDVI}+57.6425$ & $\mathrm{Ts}_{\min }=-0.459325 \mathrm{NDVI}+23.0795$ \\
2009 & $\mathrm{Ts}_{\max }=-17.6603 \mathrm{NDVI}+46.9181$ & $\mathrm{Ts}_{\min }=-1.82526 \mathrm{NDVI}+23.6458$ \\
2010 & $\mathrm{Ts}_{\max }=-25.0312 \mathrm{NDVI}+55.0796$ & $\mathrm{Ts}_{\min }=-0.597837 \mathrm{NDVI}+23.0943$ \\
2011 & $\mathrm{Ts}_{\max }=-54.4118 \mathrm{NDVI}+78.8677$ & $\mathrm{Ts}_{\min }=-3.04888 \mathrm{NDVI}+23.1797$ \\
2012 & $\mathrm{Ts}_{\max }=-22.7874 \mathrm{NDVI}+51.5211$ & $\mathrm{Ts}_{\min }=-2.21035 \mathrm{NDVI}+22.8110$ \\
2013 & $\mathrm{Ts}_{\max }=-22.3816 \mathrm{NDVI}+53.4733$ & $\mathrm{Ts}_{\min }=-2.59791 \mathrm{NDVI}+23.5056$ \\
2014 & $\mathrm{Ts}_{\max }=-32.5099 \mathrm{NDVI}+61.4427$ & $\mathrm{Ts}_{\min }=-3.12962 \mathrm{NDVI}+23.7948$ \\
\hline
\end{tabular}

Table 2. NDVI-Ts characteristic space dry-wet edge equation in Beijing-Tianjin-Hebei region from 2001 to 2014

\subsection{Analysis of the temporal and spatial changes of drought in Beijing-Tianjin-Hebei}

3.2.1 Analysis of drought time characteristics of Beijing-Tianjin-Hebei : In terms of time, the drought occurred frequently in the Beijing-Tianjin-Hebei region from 2001 to 2014. It can be said that there is drought every year and the drought characteristics are obvious (Figure 4). The fourteen-year statistics show that the overall drought situation in the Beijing-Tianjin-Hebei region is relatively serious. Excluding the 2002, 2003, 2005, 2006 and 2010 drought conditions, the TVDI values of the remaining years are high. From the severe drought in 2001 to the subsequent drought relief in 2002 and 2003, from the aggravation of drought in 2004 to the subsequent drought in 2005, 2006 and 2007; from the extremely dry areas in 2008 Three-quarters of the region accounted for one-half of the total in 2009, and there was almost no drought in 2010 . However, since 2011, the drought has obviously weakened, and the area of land with severe drought is rapidly decreasing until 
2014 has been showing a weakening trend. This result shows that the drought has occurred in the Beijing-Tianjin-Hebei region for nearly fourteen years, and it has occurred repeatedly, excluding some natural factors, and there are also some human factors. When the extremely dry areas expand, the latter. The drought in the year will be weakened.

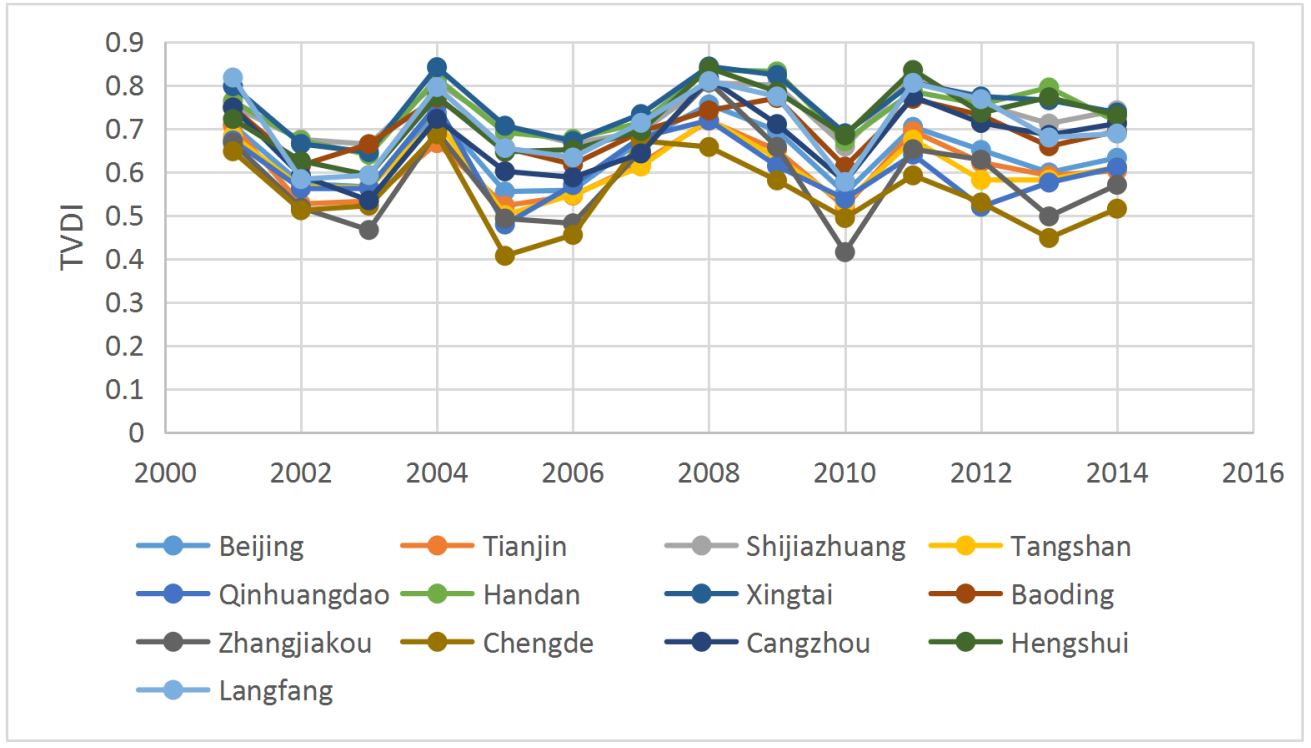

Figure 3. Changes in TVDI values from 2001 to 2014 in Beijing, Tianjin and Hebei

3.2.2 Analysis of the characteristics of the arid space in

Beijing-Tianjin: Global warming has been established in the past 100 years (Bachmair et al, 2016; Nail, 2018; Wilhite, 2000). Under this background, the aridification trend in the region is becoming more and more intense, and the aridification in northern China is gradually increasing. The boundary line between arid and semi-arid regions has reached the southernmost point of history. (Telesca, Vicente-Serrano, 2013; Van Huijgevoor et al, 2014; Fu et al, 2018). Corresponding to the above characteristics, the Beijing-Tianjin-Hebei region has less rainfall and serious soil erosion. Since April, drought has occurred throughout the whole territory. As shown in Figure 4, the area with severe drought is large and concentrated in the south of Baoding Langfang. Large areas. Among them, the extremely arid regions in 2008 were particularly serious, with the widest distribution, extending from the south of Baoding Langfang, where the drought was perennial, to the northwestern region centered on Zhangjiakou. Since 2001, the area of land with severe drought has expanded rapidly, spreading to the surrounding area around the Baoding Langfang area. Except for 2002, 2003, 2005 and 2006, it has not spread to the north of Baoding Langfang. Spreading around, and the drought in the south of Baoding gradually increased, the area with severe drought was large, mostly concentrated in Zhangzhou City, Shijiazhuang, Hengshui, Xingtai City, Handan City, and in severe cases, it will be extended to Baoding Langfang Zhangiiakou, even Beijing. Tianjin, so far in the severe drought in 2008 reached four-fifths of the Beijing-Tianjin-Hebei region, while the arid regions accounted for almost $100 \%$ of the region. The area where the drought is severely arid in the Beijing-Tianjin-Hebei region (ie, $0.8<$ TVDI $<1$, the index is shown in Table 1) is almost every year, but from the trend point of view, from 2008 to 2014, except for the area of extremely dry areas in 2008 The largest area that has been extremely dry since 2008 is gradually weakening. It can be clearly seen from Figure 3. Since 2011, the overall trend of drought in the Beijing-Tianjin-Hebei region has been declining year by year, indicating that the drought is in the Beijing-Tianjin-Hebei region. The impact is mitigating. The terrain in the north of Chengde is descending from the northwest to the southeast, and the northwest is located in the Inner Mongolia Plateau. Therefore, the climate varies greatly from north to south, and the meteorological elements are three-dimensionally distributed, making the climate diverse. The summer is mild and thunderstorm; the autumn is cool, the temperature difference between day and night is large, the frost damage is heavy, the summer is cool, the rainfall is concentrated, and there is basically no hot period, so there is basically no drought; the border of southeast of Qinhuangdao in Tangshan, Tianjin, low terrain, Yanhai, Most wetlands, so severe droughts rarely occur.

Understanding the characteristics of regional drought is a multidisciplinary research process. It is a natural process of 
interaction between biology, soil, hydrology, climate and between human beings. It is also a humanistic process in which humans interact with nature. There is a close relationship between human activities and vegetation cover and climate change. The paper does not specifically analyze the spatial distribution, time change and human activities of drought. This is the focus of our next research. In addition, the improvement of climate in the Beijing-Tianjin-Hebei region and the reduction of drought conditions are closely related to the implementation of a series of human activities such as returning farmland to forests and grasslands, and further analysis and verification are needed.

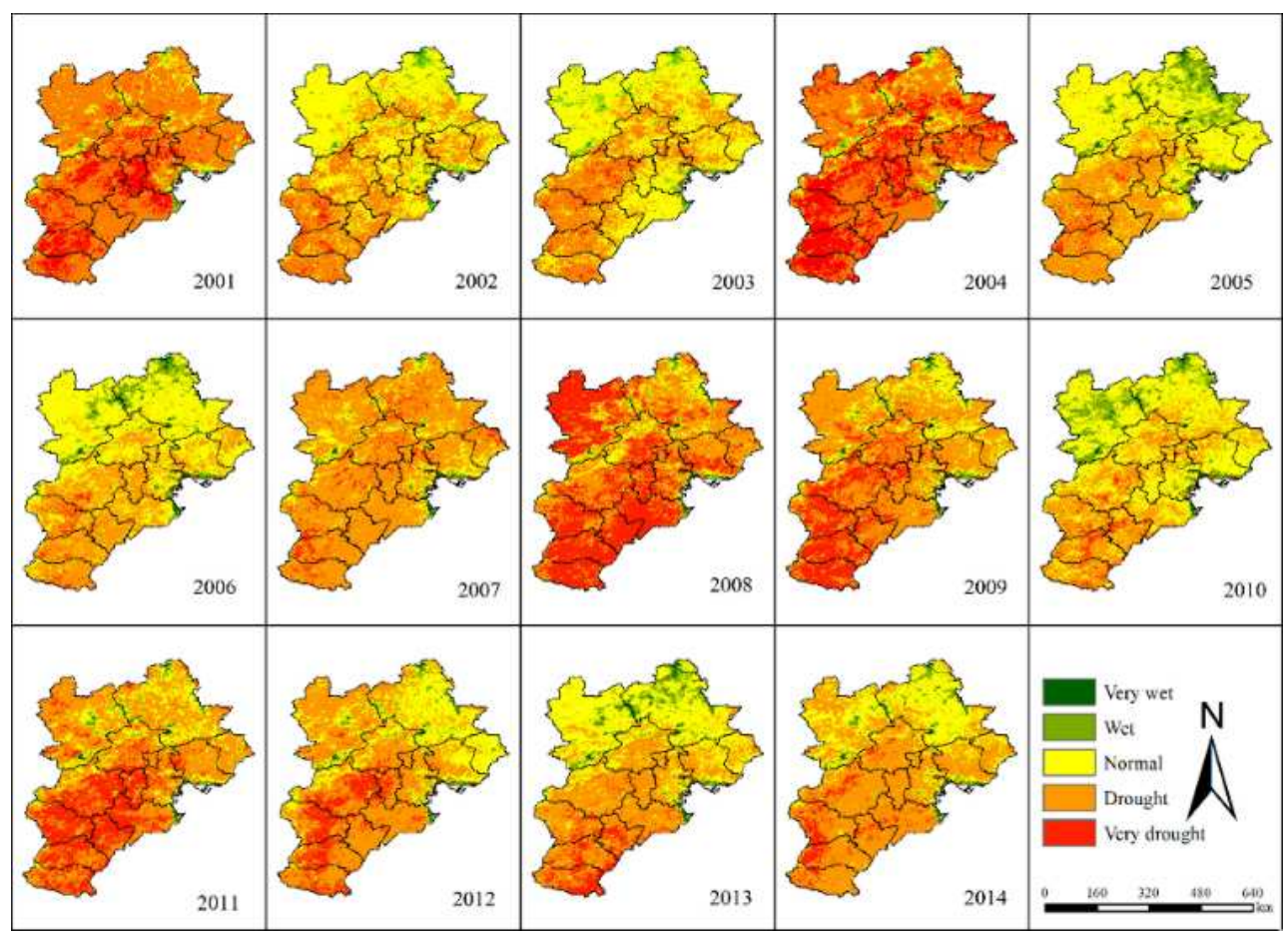

Figure 4. TVDI images from 2001 to 2014

\section{CONCLUSION}

Based on the normalized vegetation index and surface temperature data, this paper uses TVDI as a drought monitoring model to analyze the drought monitoring and time-space changes in the Beijing-Tianjin-Hebei region. The conclusions are as follows: (1) The overall degree of drought in 2001-2014 is relatively high and fluctuating. Since 2011, the degree of drought has slowed down and has been reduced year by year. Speculation may be caused by human factors (afforestation, returning farmland to forests and grassland, and conserving water sources), resulting in a gradual reduction in areas with severe drought. (2) The drought in the Beijing-Tianjin-Hebei region is widespread, and the severely arid regions are mainly concentrated in the southern and central regions. In the intensity of drought, the most frequent occurrences in 14a were Xingtai, Hengshui, Shijiazhuang, and Heilongjiang, 14 years of drought; the least number of occurrences was Chengde, a total of 4 times; the number of occurrences was second only to Chengde, Tangshan, Zhangjiakou, Qinhuangdao, a total of 7 times, the
Beijing-Tianjin-Hebei region is prone to drought and severe areas.

\section{ACKNOWLEDGEMENTS}

This study was supported by the National Natural Science Foundation of China (41801030, 41901370, 41961065); Guangxi Natural Science Foundation (2018GXNSFBA281054, 2018GXNSFBA281075，2017GXNSFDA198016); Research Foundation of Guilin University of Technology (GUTQDJJ2017069); the BaGuiScholars program of the provincial government of Guangxi (Guoqing Zhou).

\section{REFERENCES}

Bachmair S, Svensson C, Hannaford J, Barker L J, Stahl K, 2016. A quantitative analysis to objectively appraise drought indicators and modelldrought impacts. Hydrology and Earth System Sciences. 20(7):2589-2609. 
Bai Y Y, 2014. Research on surface soil moisture in salinized farmland based on multi-temporal remote sensing image. Inner Mongolia Agricultural University.

Carlson T N, Gillies R R, Perry E M, 1994. A method to make use of thermal infrared temperature and NDVI measurements to infer surface soil water content and fractional vegetation cover. Remote Sensing Reviews. 9(2):161-173.

Centritto M, Brilli F, Fodale R, Loreto F, 2011. Different sensitivity of isoprene emission, respiration and photosynthesis to high growth temperature coupled with drought stress in black poplar (Populus nigra) saplings. Tree Physiology. 31(3):275-286.

Chen B, Zhang X X, Hua K, Xu W, 2013. Application of Temperature Vegetation Dryness Index (TVDI) in Grassland Drought Monitoring. Arid Land Geography. 36(05):930-937.

Fu Q, Zhou Z Q, Li T X, Liu D, Hou R J, Cui S, Yan P R, 2018. Spatiotemporal characteristics of droughts and floods in northeastern China and their impacts on agriculture. Stochastic Environmental Research and Risk Assessment. 32(10):2913-2931.

Goward S N. Hope A S, 1989. Evapotranspiration from combined reflected solar and emitted terrestrial radiation: Preliminary F1FE results from AVHRR data. Advances in Space Research. 9(7):239-249.

Liu X J, Zhang J Q, Ma D L, Bao Y L, Tong Z J, Liu X P, 2013. Dynamic risk assessment of drought disaster for maize based on integrating multi-sources data in the region of the northwest of Liaoning Province, China. Natural Hazards. 65(3):1393-1409.

Moran M S, Clarke T R, Inoue Y, Vidal A, 1994. Estimating crop water deficit: using the relation between surface-air temperature and spectral vegetation index. Remote Sensing of Environment. 49(3):246-263.

Nail M, Zhang K, Martin K, 2018. Analysis of drought and vuln erability in the North Darfur region of Sudan. Land Degradatio $n$ \& Development. 29(12): 4424-4438.

Nait-Ali B, Oummadi S, Portuguez E, Alzina A, Smith D S, 2017. Thermal conductivity of ceramic green bodies during drying. Journal of the European Ceramic Society. 37(4):1839-1846.

Nemani R, Pierce L, Running S, Goward S, 1993. Developing satellite-derived estimates of surface moisture status. Journal of
Applied Meteorology. 32(3):548-557.

Price J C, 1990. Using spatial context in satellite data to infer regional scale evapotranspiration. IEEE Transactions on Geoscience and Remote Sensing. 28(5):940-948.

Liu Q, Zhang G L, Shahzad A, Wang X P, Wang G D, Pan Z K, Zhang J H, 2019. SPI-based drought simulation and prediction using ARMA-GARCH model. Applied Mathematics and Computation. 355(1):96-107.

Qi S H, 2004. Drought Monitoring Remote Sensing Model and China's Drought Time and Space Analysis. Beijing: Chinese Academy of Sciences.

Sandholt I, Rasmussen K, Andersen J, 2002. A simple interpretation of the surface temperature/ vegetation index space for assessment of surface moisture status. Remote Sensing of Environment. 79(2):213-224.

Sun Z Y, Zhang J Q, Zhang Q, Hu Y, Yan D H, Wang C Y, 2014. Integrated risk zoning of drought and waterlogging disasters based on fuzzy comprehensive evaluation in Anhui Province, China. Natural Hazards. 71(3):1639-1657.

Telesca L, Vicente-Serrano S M, 2013. Power spectral characteristics of drought indices in the Ebro river basin at different temporal scales. Stochastic Environmental Research \& Risk Assessment. 27(5):1155-1170.

Van Huijgevoort M H J, Van Lanen H A J, Teuling A J, Uijlenhoet R, 2014. Identification of changes in hydrological drought characteristics from a multi-GCM driven ensemble constrained by observed discharge. Journal of Hydrology. 512(5):421-434.

Wang Q F, Wu J J, Lei T J, He B, Wu Z T, Liu M, Mo X Y, Geng G P, Li X H, Zhou H K, Liu D C, 2014. Temporal-spatial characteristics of severe drought events and their impact on agriculture on a global scale. Quaternary International. 349:10-21.

Wilhite D A, 2000. Drought as a natural hazard: Concepts and definitions. Drought A Global Assessment. (1):3-18.

Zhang J, Chen H, Zhang Q, 2019. Extreme drought in the recent two decades in northern China resulting from Eurasian warming. Climate Dynamics. 52(5-6):2885-2902.

Zhang L Y, Yang D, Ma L, 2017. Characteristics and Causes of Meteorological Drought in Beijing-Tianjin-Hebei Region. Journal of Hydroelectric Engineering. 36(12):124-156. 